\title{
Methanolic Extracts from Cultivated Mushrooms Affect the Production of Fumonisins B and Fusaric Acid by Fusarium verticillioides
}

\author{
Daniel Merel $^{1,2}$, Jean-Michel Savoie ${ }^{3, * \mathbb{C}}$, Gerardo Mata ${ }^{1, * \mathbb{D}}$, Dulce Salmones ${ }^{1}$, Carlos Ortega ${ }^{1}$, \\ Vessela Atanasova $^{3}$, Sylvain Chéreau ${ }^{3}$, Juan L. Monribot-Villanueva ${ }^{2}$ \\ and José A. Guerrero-Analco ${ }^{2, *}$ \\ 1 Red Manejo Biotecnológico de Recursos (RMBR), Instituto de Ecología (A.C), Xalapa 91073, Mexico; \\ danielmerel@hotmail.com (D.M.); dulce.salmones@inecol.mx (D.S.); carlos.ortega@inecol.mx (C.O.) \\ 2 Red Estudios Moleculares Avanzados (REMAV), Instituto de Ecología (A.C), Xalapa 91073, Mexico; \\ juan.monribot@inecol.mx \\ 3 INRAE, Mycology and Food Safety (MycSA), F-22882 Villenave d'Ornon, France; \\ vessela.atanasova@inrae.fr (V.A.); sylvain.chereau@inrae.fr (S.C.) \\ * Correspondence: jean-michel.savoie@inra.fr (J.-M.S.); gerardo.mata@inecol.mx (G.M.); \\ joseantonio.guerrero@inecol.mx (J.A.G.-A.); Tel.: +33-557-122-496 (J.-M.S.); \\ $+52-228-842-1800$ (G.M. \& J.A.G.-A.)
}

Received: 22 April 2020; Accepted: 27 May 2020; Published: 2 June 2020

\begin{abstract}
The maize pathogen Fusarium verticillioides and their mycotoxins cause damage to plants, animals, and human health. This work aimed to evaluate the effect of crude extracts (CEs) from Agaricus subrufescens, Lentinula edodes, and Pleurotus ostreatus fruiting bodies on in vitro production of biomass and mycotoxins by two strains of $F$. verticillioides. Stipes and pilei were separated before extraction for A. subrufescens and L. edodes. Comparative metabolomics and dereplication of phenolic compounds were used to analyze all CEs. Mushroom CEs did not significantly inhibit the production of mycelial biomass at concentrations of $2 \mathrm{mg} \mathrm{mL}^{-1}$. CEs from A. subrufescens (stipes and pilei) and L. edodes pilei inhibited the production of fumonisins $\mathrm{B} 1+\mathrm{B} 2+\mathrm{B} 3$ by $54 \%$ to $80 \%$, whereas $\mathrm{CE}$ from P. ostreatus had no effect. In contrast, $\mathrm{CE}$ from $L$. edodes stipes dramatically increased the concentration of fumonisins in culture media. Fusaric acid concentration was decreased in cultures by all CEs except $L$. edodes stipes. Differences in phenolic composition of the extracts may explain the different effects of the CE treatments on the production of mycotoxins. The opposing activities of stipes and pilei from L. edodes offer an opportunity to search for active compounds to control the mycotoxin production by F. verticillioides.
\end{abstract}

Keywords: mycotoxins; biocontrol; mushroom metabolomics; phenols; basidiomycetes

Key Contribution: Crude extracts from A. subrufescens and L. edodes mushrooms have a potential to inhibit mycotoxin production by F. verticillioides and are worth being used as products for protecting maize from infection and contamination.

\section{Introduction}

Both governmental and non-governmental organizations responsible for food safety of developed and developing countries are concerned for the contaminations of maize (Zea mays L.) by fungi and their mycotoxins. This contamination is the source of a variety of negative consequences to the health of livestock and humans feeding on maize [1,2]. Fusarium verticillioides (Sacc.) Nirenberg is commonly isolated from diseased maize plants with symptoms of ear and kernel rot from tropical 
areas [3]. This species is known to be a producer of fumonisins and fusaric acid (FA) mycotoxins that are found in maize kernels [4]. More than fifty fumonisins have been reported and clustered into A, B, C, and P groups based upon their chemical structures and phytotoxicity level, with fumonisins B1 (FB1), B2 (FB2), and B3 (FB3) as the most common types found. Specifically, FB1 can comprise from $70 \%$ to $80 \%$ of the total fumonisins [5,6] found when the fungus is cultured on maize or in liquid medium. Alarmingly, epidemiological studies have associated a higher frequency of human esophageal cancer with the presence of FB1 within foods in China, Iran, and South Africa [7,8]. According to the International Agency for Research on Cancer, FB1 is classified as a possible carcinogenic to humans (group 2B) [9]. Furthermore, maternal consumption of fumonisins in maize grains or processed food made from maize during early gestation cause spinal bifida and anencephalic births [10,11]. Additionally, the fumonisin intake through contaminated feed is responsible for animal fatal toxicosis, such as leukoencephalomalacia in horses [12,13] and pulmonary edema in swine [14]. FA, the other mycotoxin produced by F. verticillioides and commonly detected in grains, is known for its high phytotoxicity. It can inhibit maize seedling development [15] and exhibit adverse effects on tissues of cotton, banana, and tomato plants [16-18]. Recent studies have found that FA induces DNA damage and necrosis in human hepatocellular carcinoma cells $[19,20]$, apoptosis in human cancerous esophageal cells [21], and mitochondrial stress in human cervix carcinoma cells [22]. FA also shows detrimental outcomes towards animals by causing negative neurochemical effects in rats [23] and teratogenic effects in zebrafish [24], and it has been reported to synergize the toxicity of FB1 [25].

Fungal growth and mycotoxin accumulation in grains is affected by climatic conditions during pre-harvest and harvest stages. Furthermore, inadequate conditions of grain storage and transport can promote the toxigenic fungi growth and contamination [26]. A current strategy proposed to control phytopathogenic fungi and their mycotoxin production is the application of natural products that inhibit the growth of the toxic fungi and/or the production of pernicious metabolites. This approach is suitable for applications in agriculture due to their low toxicity that minimizes the potential for environmental impacts to agriculture and harmful effects to human health [27].

Phenolic compounds are specialized metabolites that have been effective to inhibit the mycelial growth and toxin production of fungi $[28,29]$ and generally are known to have low toxicity. Namely, addition of phenolic acids [30,31] and flavonoids [32] in culture media reduced fumonisin production of F. verticillioides. Basidiomycete mushrooms also produce antifungal compounds [33]. In a review of the literature from 1999 to 2012, extracts from 52 species had been reported for their antifungal properties [34]. More than $80 \%$ of these species are edible mushrooms, since their extracts might be generally recognized as safe for consumption. Most of the studies have focused on the inhibition of fungal growth by crude or partially simplified extracts and have not identified specific compounds responsible for their antifungal activity. Only a few of these were conducted to identify the effects of the extracts from these edible mushrooms against mycotoxin production, leaving these organisms untapped sources for preventing and reducing mycotoxins in cereal products [35]. Agaricus subrufescens Peck, Lentinula edodes (Berk.) Pegler, and Pleurotus ostreatus (Jacq.) P. Kumm. (commonly known as almond mushroom, shiitake, and oyster mushroom, respectively) are gourmet mushrooms that are cultivated worldwide. The aim of this work was to evaluate the potential of crude extracts (CEs) obtained from fruiting bodies of A. subrufescens, L. edodes, and P. ostreatus to inhibit the production of fumonisins and FA by F. verticillioides, and to begin to identify specific chemical compounds responsible for this bioactivity.

\section{Results}

\subsection{Extraction Yields}

The yield of methanolic extracts varied with samples, from $13.2 \%$ in stipe of $A$. subrufescens to $29.6 \%$ in whole sporophore of P. ostreatus (Table 1). In L. edodes pileus, an amorphous powder spontaneously precipitated during the evaporation of methanol. The precipitate ( $14.3 \%$ of the initial biomass) was 
separated from its liquors by decantation before drying for obtaining CE used for biological tests and metabolomics.

Table 1. Dry biomasses of mushroom, crude extracts obtained (CE), and extraction yields obtained from A. subrufescens pileus (As-P) and stipe (As-S), L. edodes pileus (Le-P) and stipe (Le-S), and P. ostreatus sporophore (Po).

\begin{tabular}{ccccc}
\hline Strain & Sporophore Structure & Dry Biomass $(\mathrm{g})$ & CE $(\mathrm{g})$ & Yield (\%) \\
\hline \multirow{2}{*}{ IE-832 } & As-P & 44.0 & 10.1 & 23.0 \\
& As-S & 73.9 & 9.8 & 13.2 \\
IE-40 & Le-P & 137.0 & 25.2 & 18.4 \\
IE-38 & Le-S & 59.9 & 17.1 & 28.5 \\
& Po & 80.0 & 23.7 & 29.6 \\
\hline
\end{tabular}

\subsection{Effect of CEs on Fungal Growth of F. verticillioides Fv63 and MY3 Strains}

All the quantities of mycelial biomass produced by F. verticillioides strain Fv63 were significantly higher in cultures treated with CEs of A. subrufescens stripe (As-S), A. subrufescens pileus (As-P), L. edodes stipe (Le-S), L. edodes pileus (Le-P), and P. ostreatus sporophore (Po) when compared to the control (Figure 1a). On the other hand, treatment of the MY3 strain of F. verticillioides with these CEs demonstrated no effect on growth compared to the control (Figure 1b).

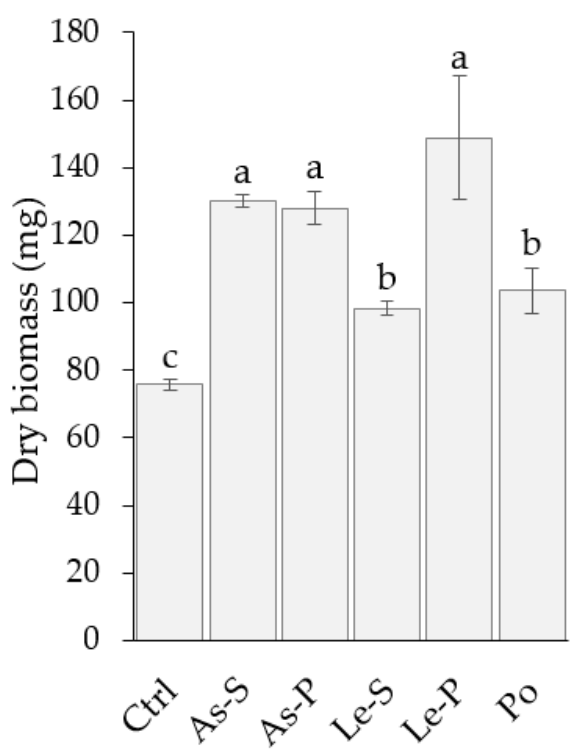

(a)

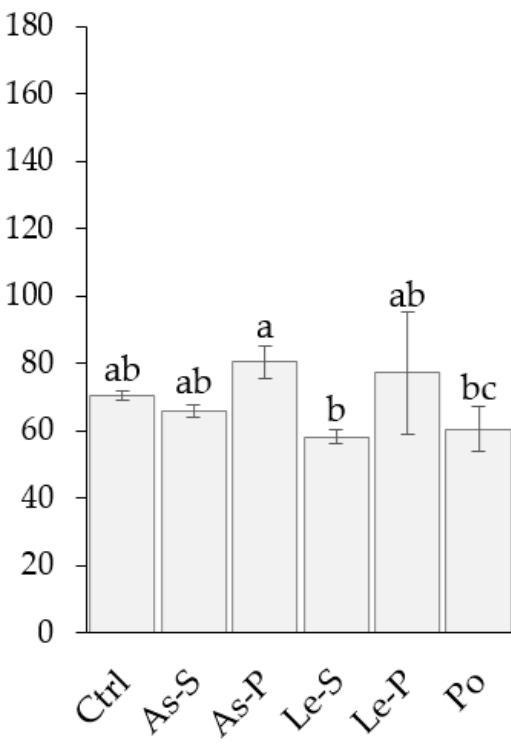

(b)

Figure 1. Fungal biomass of $F$. verticillioides strains produced in liquid media supplemented with 2 $\mathrm{mg} \mathrm{mL}^{-1}$ crude extracts. (a) Represents fungal biomass measurements for all treatments of strain Fv63. (b) Represents fungal biomass measurements for all treatments of strain MY3. Fungal biomass data was recorded for three replicates and the \pm standard deviation is represented by the error bars. Letters $(a, b$, and $c)$ indicate significant differences between treatments and control, according to Tukey's Test $(\alpha=0.05)$. Extracts are represented by the following abbreviations: Control (Ctrl), CEs from A. subrufescens stipe (As-S) and pileus (As-P), L. edodes stipe (Le-S) and pileus (Le-P), P. ostreatus sporophore (Po).

\subsection{Effect of CEs on Fumonisin Production by F. verticillioides Fv63}

CE from As-P was demonstrated to inhibit the FB1 and FB2 production of the Fv63 strain by $79 \%$ and $92 \%$ respectively, and demonstrated similar activity against FB3 production (69\%) (Figure 2). As-S significantly inhibited FB2 production (86\%) and decreased FB1 (46\%) and FB3 (36.8\%) concentrations. CE from Le-P inhibited the production of the three fumonisins (64.5\% for FB1, 84.37\% 
for FB2, and 77.6\% for FB3), while CE from Le-S significantly increased their production (Figure 2a-c). $\mathrm{FB} 1+\mathrm{FB} 2+\mathrm{FB} 3$ production was inhibited by As-P and Le-P treatments ( $80.2 \%$ and $70.6 \%$, respectively), whereas Le-S increased their accumulation by 4 -fold (Figure 2d).
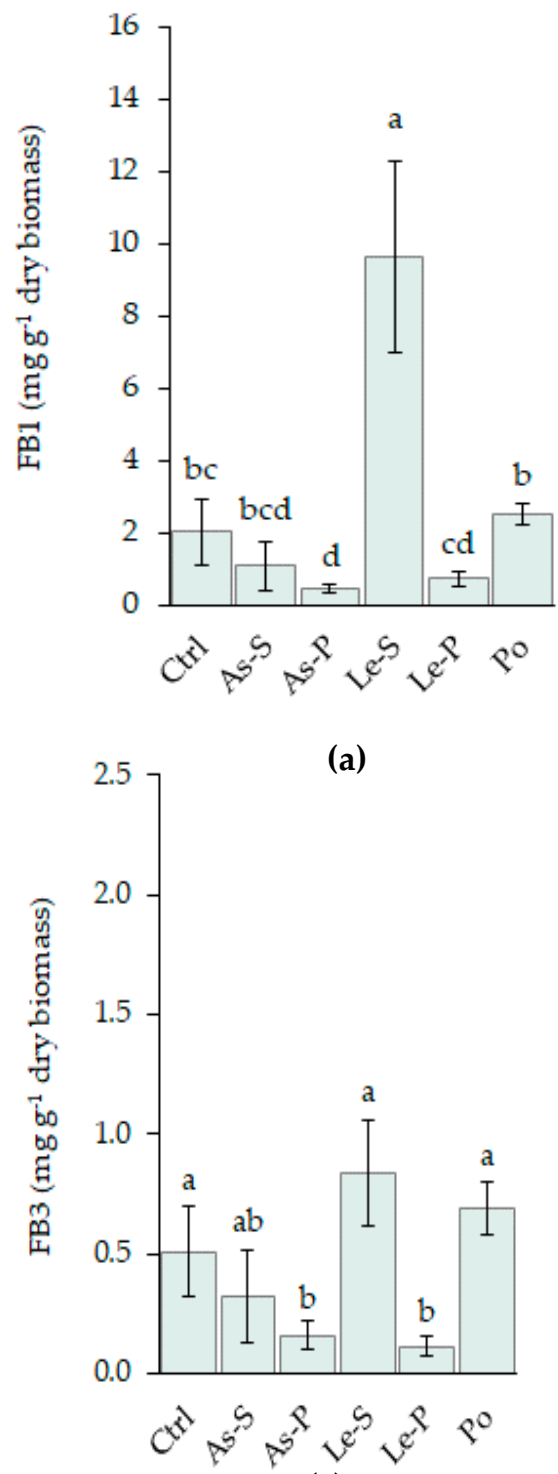

(c)

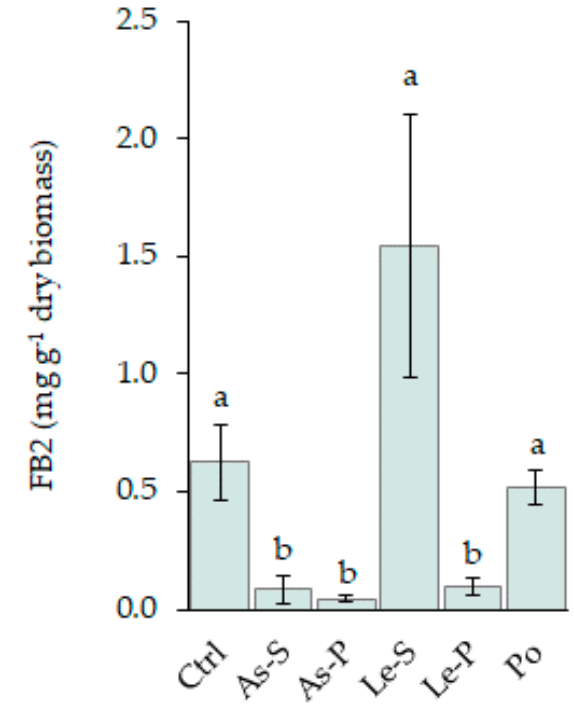

(b)

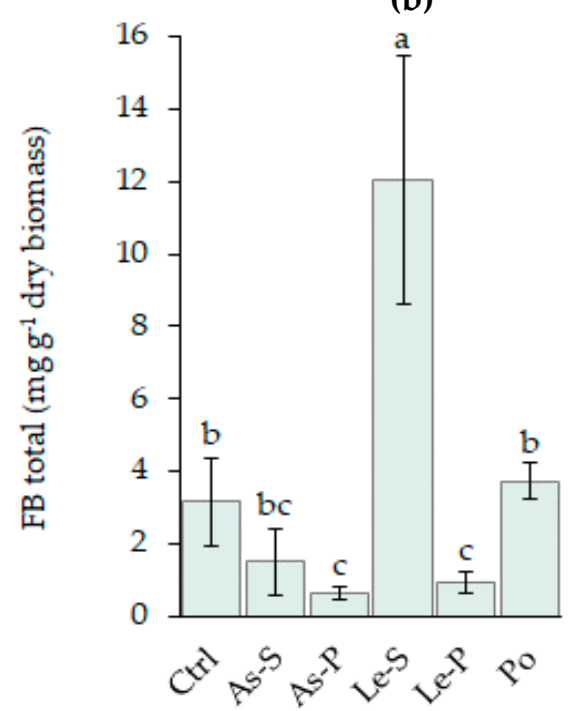

(d)

Figure 2. Effects of CE treatments of As-S, As-P, Le-S, Le-P, and Po on fumonisins B1 (a), B2 (b), B3 (c), and total (B1 + B2 + B3) fumonisin (d) produced by F. verticillioides (Fv63 strain) in glucose, amylopectin, yeast extract, and peptone (GAYEP) medium supplemented with $2 \mathrm{mg} \mathrm{mL}^{-1}$ CEs. Data are represented as the mean mycotoxin production of three replicated cultures and three measurements per cultures with the \pm standard deviation represented by error bars. Letters $(a, b$, and $c)$ indicate significant differences between treatments and control according to Tukey's Test $(\alpha=0.05)$.

Under these conditions, the MY3 strain produced less fumonisins than Fv63 and detection limits only allowed the quantitation of FB1 in this strain. Treatment with As-S and AS-P extracts reduced the FB1 production below the limit of detection, while no difference in FB1 production was demonstrated by treatment with the other CEs compared to the control. Le-S treatment was found to increase the concentration of FB1 by $200 \%$, whereas Le-P decreased it by $43 \%$. The difference between Le-S and Le-P was found to be significant (Figure 3a). 


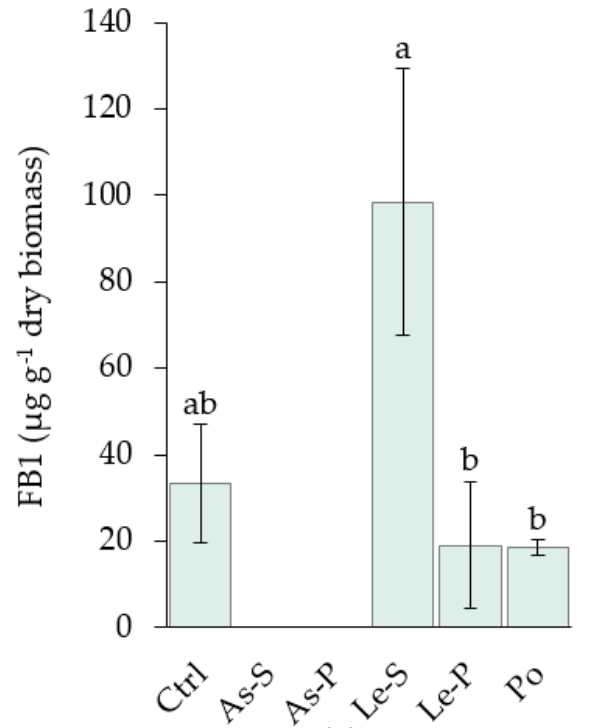

(a)

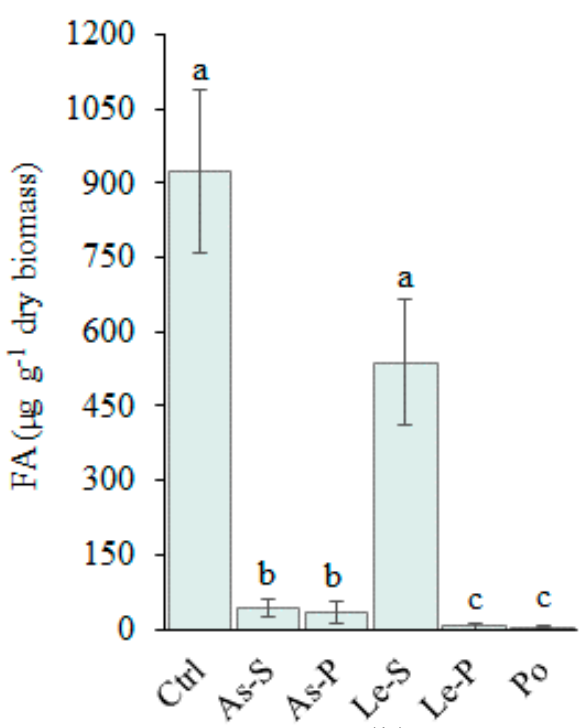

(b)

Figure 3. FB1 and FA produced by F. verticillioides (MY3 strain) in glucose, amylopectin, yeast extract, and peptone (GAYEP) medium supplemented with $2 \mathrm{mg} \mathrm{mL}^{-1} \mathrm{CEs}$. (a) FB1 production versus treatment with different CEs, (b) FA production versus treatment with different CEs. Data are represented by the mean of three replicated cultures and three measurements of FB1 or FA production and error bars represent the \pm standard deviation. Letters $(a, b$, and $c)$ indicate significant differences between treatments and the control, according to Tukey's Test $(\alpha=0.05)$. Extracts were: Control (Ctrl), CEs from A. subrufescens stipe (As-S) and pileus (As-P), L. edodes stipe (Le-S) and pileus (Le-P), P. ostreatus sporophore (Po).

\subsection{Effect of CEs on Fusaric Acidproduction by F. verticillioides MY3}

FA production by MY3 was almost completely inhibited by treatment with the CEs in the following order Po $=$ Le-P $>$ As-P $=$ As-S (99.5-95.3\%). FA production was not significantly affected by treatment with L. edodes stipe CE (Figure 3b).

\subsection{Metabolomic Analysis and Chemical Profiling of the CEs}

The metabolome similarities of all CEs were evaluated by a principal components analysis (PCA) and a fold change analysis that consider each feature (retention time/mass-to-charge ratio (m/z) pairs). The sample grouping as the result of PCA showed significant differences in chemical composition of the CEs of the three species of mushroom within the first two principal components (PC1 and PC2), which explains $46.2 \%$ and $35 \%$ respectively, of the total variance (Figure 4). Interestingly, only weak intraspecific differences were observed in the PCA analysis of CEs from As-s and As-P, while in L. edodes, the compositions of the Le-S and Le-P were found to be different (Figure 4). 


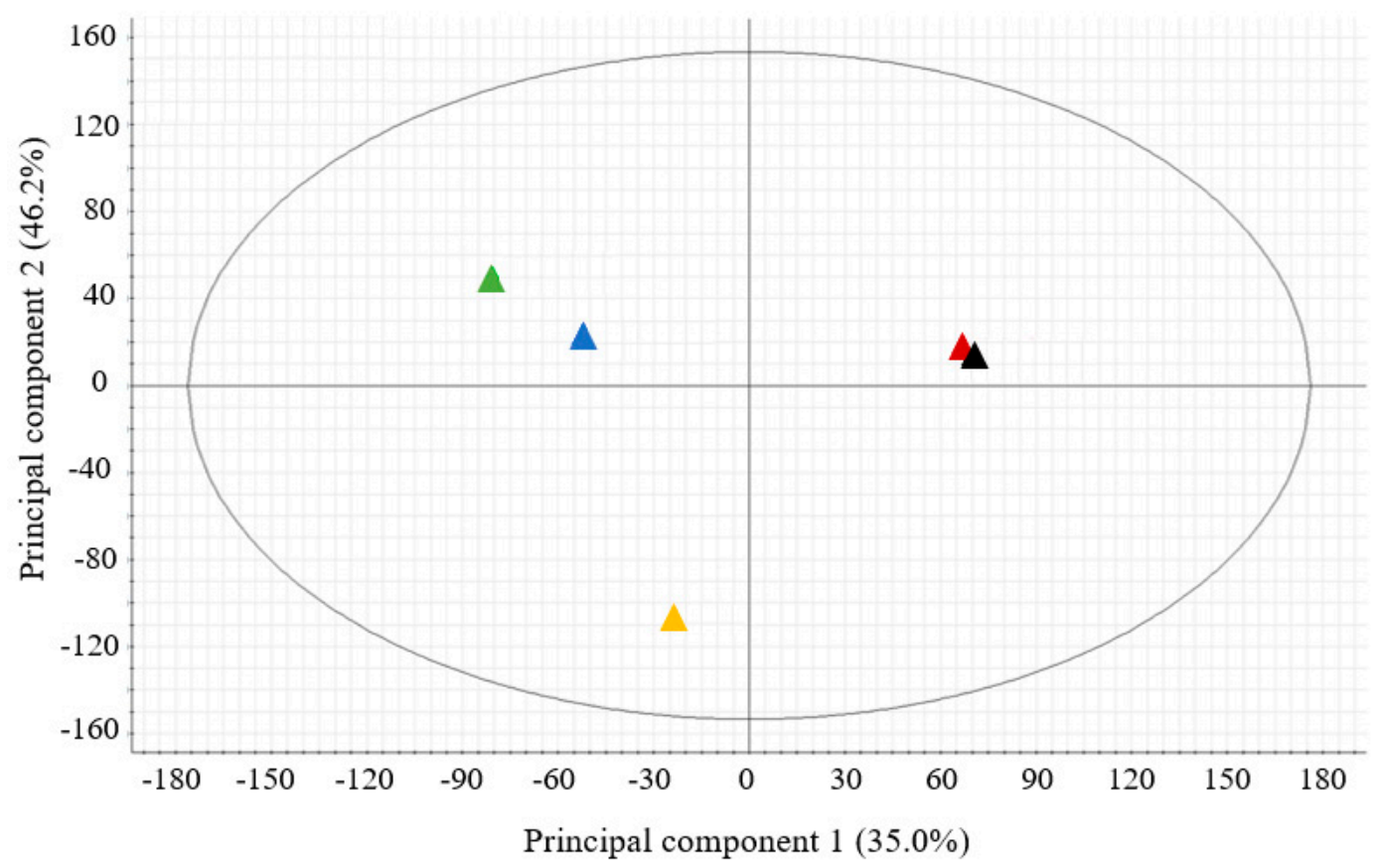

Figure 4. Principal component analysis (PCA) of ions detected in the CEs from A. subrufescens ( $\triangle$ pileus and $\Delta$ stipe), L. edodes ( $\Delta$ pileus and $\Delta$ stipe), and P. ostreatus ( $\triangle$ whole sporophore).

Since biological activities and chemical compositions of CEs from Le-P and Le-S were found to be different, further investigations were performed on these extracts. 349 ions were detected in Le-P CE whereas 242 ions were detected in Le-S CE. Of these ions, 156 were detected at a similar abundance (Figure 5). Further metabolomic analysis allowed for the putative identification of ions that significantly differed between these samples. Adenine, L-phenylalanine, 3-amino-2-naphthoic acid and (22E,24x)-ergosta-4,6,8,22-tetraen-3-one were metabolites tentatively identified to be present only in Le-P, and farnesyl acetone was only identified in Le-S (Table 2).

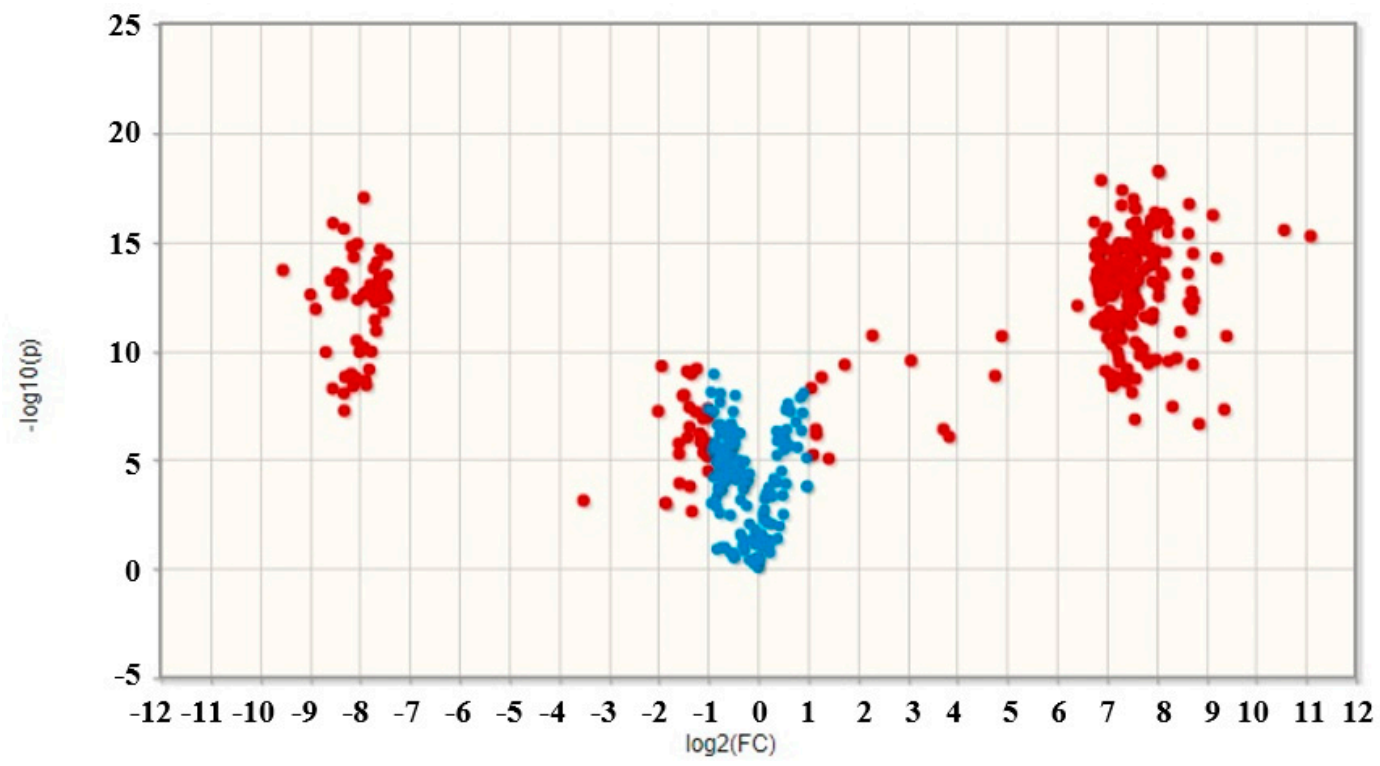

Figure 5. Volcano plot of ions detected in L. edodes CEs. Ions with significantly different abundance (fold change $>2$ ) between the samples $(\bullet$ ), ions with no significant difference in abundance between the samples $(\bullet)$. 
Table 2. Metabolites putatively identified in the CEs from L. edodes that are significantly present in only one part of the sporophore. Levels of metabolite identification (LMI) [36] is included as well as mass-to-charge ratio $(\mathrm{m} / \mathrm{z})$, the adducts, and retention time (RT) of each compound.

\begin{tabular}{|c|c|c|c|c|c|c|c|c|c|}
\hline Metabolite & LMI & Formula & $\begin{array}{c}m / z \\
\text { Experimental }\end{array}$ & $\begin{array}{c}m / z \\
\text { Theoretical }\end{array}$ & $\begin{array}{l}\text { Error } \\
(\mathrm{ppm})\end{array}$ & Adduct & RT & $\begin{array}{c}\text { Product } \\
\text { Ions }(m / z)\end{array}$ & CE \\
\hline L-Phenylalanine & 2 & $\mathrm{C}_{9} \mathrm{H}_{11} \mathrm{NO}_{2}$ & 166.0864 & 166.0863 & -0.6 & {$[\mathrm{M}+\mathrm{H}]^{+}$} & 1.66 & $\begin{array}{l}120.0807 \\
103.0536\end{array}$ & Pileus \\
\hline Adenine & 2 & $\mathrm{C}_{5} \mathrm{H}_{5} \mathrm{~N}_{5}$ & 136.0618 & 136.0618 & 0.0 & {$[\mathrm{M}+\mathrm{H}]^{+}$} & 1.94 & $\begin{array}{c}119.0349 \\
92.0234\end{array}$ & Pileus \\
\hline $\begin{array}{c}\text { 3-amino-2- } \\
\text { naphthoic acid } \\
(22 \mathrm{E}, 24 \mathrm{x})\end{array}$ & 2 & $\mathrm{C}_{11} \mathrm{H}_{9} \mathrm{NO}_{2}$ & 188.0712 & 188.0706 & -3.2 & {$[\mathrm{M}+\mathrm{H}]^{+}$} & 2.30 & $\begin{array}{l}170.0601 \\
142.0651\end{array}$ & Pileus \\
\hline $\begin{array}{l}\text {-Ergosta-4,6,8,22 } \\
\text {-tetraen-3-one }\end{array}$ & 3 & $\mathrm{C}_{28} \mathrm{H}_{40} \mathrm{O}$ & 393.3142 & 393.3152 & 2.5 & {$[\mathrm{M}+\mathrm{H}]^{+}$} & 18.46 & No* & Pileus \\
\hline $\begin{array}{l}\text { Farnesyl } \\
\text { acetone }\end{array}$ & 2 & $\mathrm{C}_{18} \mathrm{H}_{30} \mathrm{O}$ & 245.2272 & 245.2269 & 1.2 & {$\left[\mathrm{M}+\mathrm{H}-\mathrm{H}_{2} \mathrm{O}\right]^{+}$} & 16.39 & $\begin{array}{l}107.0847 \\
109.1005 \\
123.1160\end{array}$ & Stipe \\
\hline
\end{tabular}

*: no ions were found for this metabolite.

\subsection{Dereplication of Phenolic Compounds}

The analysis detected five phenolic compounds in the CEs, one anthraquinone and four phenolic acids (Table 3). Chrysophanol was the most abundant compound contained in all sporophore structures (130.3-26,226.2 $\left.\mu \mathrm{g} \mathrm{g}^{-1}\right)$ followed by protocatechuic acid $\left(6.2-1245.9 \mu \mathrm{g} \mathrm{g}{ }^{-1}\right)$, shikimic acid (24.3-44.6 $\left.\mu \mathrm{g} \mathrm{g}^{-1}\right)$, and 4-hydroxybenzoic acid (6.2-36.9 $\left.\mu \mathrm{g} \mathrm{g}^{-1}\right)$. CE from Po, Le-S, and Le-P were the only samples that contained 4-hydroxyphenylacetic acid (5.6, 5.2, and $9.1 \mathrm{\mu g} \mathrm{g}^{-1}$, respectively). The lower concentrations of phenolic compounds detected were for sinapic acid in Po, Le-P, and As-S (5.0, 7.7, and $8.2 \mu \mathrm{g} \mathrm{g}^{-1}$, respectively). Finally, Po was the only CE that was found to contain trans-cinnamic acid at a low concentration $\left(5.0 \mu \mathrm{g} \mathrm{g}^{-1}\right)$ (Table 3).

Table 3. Phenolic compounds identified and quantified in CEs from A. subrufescens, L. edodes and P. ostreatus sporophores.

\begin{tabular}{ccccccrr}
\hline \multirow{2}{*}{$\begin{array}{c}\text { Species and } \\
\begin{array}{c}\text { Sporophore } \\
\text { Structure }\end{array}\end{array}$} & ShA & CiA & PrA & HyBA & SiA & HyPA & Ch \\
\cline { 2 - 7 } & $44.6 \pm 2.4$ & N/D & $7.9 \pm 0.1$ & $6.2 \pm 0.6$ & N/D & N/D & $131.1 \pm 0.4$ \\
As-P & N/D & N/D & $7.4 \pm 0.1$ & $7.9 \pm 0.2$ & $8.3 \pm 0.3$ & N/D & $135.0 \pm 0.7$ \\
As-S & $34.5 \pm 9.4$ & N/D & $6.2 \pm 4.9$ & $37.0 \pm 0.6$ & $7.7 \pm 0.7$ & $9.2 \pm 1.1$ & $130.4 \pm 0.3$ \\
Le-P & $24.4 \pm 1.5$ & N/D & $6.2 \pm 4.4$ & $11.3 \pm 0.2$ & N/D & $5.2 \pm 0.4$ & $130.7 \pm 0.4$ \\
Le-S & $71 \%$ & & $100 \%$ & $30 \%$ & $0 \%$ & $56 \%$ & $100 \%$ \\
S/P & $42.3 \pm 2.6$ & $5.0 \pm 0.2$ & $7.9 \pm 0.1$ & $7.7 \pm 0.3$ & 5.0 & $5.6 \pm 0.6$ & $130.4 \pm 1.1$ \\
Po & & &
\end{tabular}

Phenolic compounds: shikimic acid (ShA), trans-cinnamic acid (CiA), protocatechuic acid (PrA), 4-hydroxy-benzoic acid (HyBA), sinapic acid (SiA), 4-hydroxy-phenylacetic acid (HyPA), and chrysophanol (Ch). Not detected (N/D).

\section{Discussion}

In the present work, we evaluated crude methanolic extracts of three edible mushroom species Agaricus subrufescens, Lentinula edodes, and Pleurotus ostreatus against the culture media from two strains of Fusarium verticillioides. Antifungal activity of mushroom extracts and isolated compounds have been shown for several species, which are mainly edible mushrooms, since they were the most studied because their derivatives might be generally recognized as safe for use [33]. Culture filtrates of A. subrufescens and L. edodes inhibited the mycelial growth of different phytopathogenic fungi such as Fusarium solani and F. oxysporum [37,38]. An extract from A. subrufescens fruiting bodies reduced growth of saprophytic fungi Aspergillus spp., Penicillium spp., and Trichoderma spp. [39]. Additionally, water extracts from spent mushroom substrates of L. edodes suppressed mycelial growth of the rice blast fungus Pyricularia oryzae [40]. In addition, ethanolic extracts of Hydnum repandum, a mycorrhizal species commonly known as the sweet tooth or hedgehog mushroom and broadly distributed in Europe and Asia, had strong antifungal effects on various Fusarium species, including F. verticillioides [41]. 
Nonetheless, to date, there are no previous studies that showed inhibition of $F$. verticillioides by extracts from A. subrufescens, L. edodes, or P. ostreatus [35]. The concentration of CEs used in this study was selected based on the previous report of Stojkovic et al. [39], who identified antifungal activity at a concentration around $2 \mathrm{mg} \mathrm{mL}^{-1}$ of a methanolic extract from A. subrufescens (or A. brasiliensis) fruiting bodies, and after a preliminary concentration-response analysis on both mycelial growth and mycotoxin production, using whole fruiting bodies of $A$. subrufescens. In our study, we did not observe any growth inhibition of the two Fusarium strains, and instead observed growth-stimulating effects of the cultured Fv63 treated with all the CEs. Extracts from mushrooms are considered to be rich in phenolic compounds and these molecules are thought to be the source of their anti-fungal and antioxidant activities [42]. It has been established that the effects of phenolic acids such as ferulic acid demonstrated dose-dependent effects on F. verticillioides growth, significantly reducing growth upon treating the culture with $20 \mathrm{mM}$ of this compound and stimulating growth at $1.0 \mathrm{mM}$ treatments [43]. The low concentrations of each phenolic compound, including ferulic acid in our treatments of the culture media, might be at the origin of the observed absence of inhibition on mycelial growth in the present work. Treatment of cultures with higher concentrations of these extracts may result in the inhibition of fungal biomass growth.

The main objective of this study was to search for inhibiting effects of CEs and their chemical composition on mycotoxin production independent of mycelial growth. Treatment of culture media of the Fv63 strain of F. verticillioides with $2 \mathrm{mg} \mathrm{mL}^{-1}$ CEs of pileus and stipe tissues of A. subrufescens, L. edodes, and P. ostreatus resulted in varied effects on FB1, FB2, FB3, and total fumonisin concentration depending on mushroom species and tissue. CEs of As-P and As-S generally inhibited fumonisin production at varying levels. CEs of L. edodes demonstrated dramatically different effects on fumonisin production depending on the tissue, with pileus extract demonstrating significantly inhibited production and stipe extract stimulating their production. P. ostreatus was found to have no significant effect on the fumonisin production. FB1 production in MY3 was inhibited by treatment with As-S and As-P extracts. Treatment with Le-S and Le-P extracts had opposing effects on FB1 production by the MY3 strain, with Le-S stimulating FB1 production and Le-P having no effect. The effects of the CEs on FA production were also evaluated in MY3. All extracts, except for Le-S, were found to significantly inhibit FA production. Given the varied effects of the extracts on fumonisin and FA production as the result of tissue and mushroom species, we hypothesized that chemical differences in phenolic composition and concentration were responsible in part for these differences in the biological activity.

To explore this hypothesis, we subjected the CEs to metabolomic analysis using liquid chromatography coupled to accurate mass spectrometry. A PCA of each CE revealed significant differences between the chemical composition of the CEs that corroborated the trends in biological activity that were observed. All three mushroom species extracts were found to have distinct metabolomic profiles, and variation between pileus and stipes of $L$. edodes were also distinctly different. Molecular annotation of the metabolomic profiles revealed differences in the phenolic composition between these extracts. Phenolic compounds are some of the specialized metabolites that have been identified as responsible for F. verticillioides growth inhibition $[28,30,44]$. These lipophilic compounds are thought to diffuse through the fungal membrane, penetrate the cell, and interfere in metabolic pathways involved in cell wall and membrane formation and transmembrane transport [45]. It has been reported that lipophilic compounds displayed a more efficient antifungal activity on other Fusarium species, such as F. graminearum [46]. The phenolics are also known to modulate the production of mycotoxins by Fusarium spp. [47], for instance fumonisins [28,48], but with variations among strains and species [30]. We identified and quantified the following phenolic acids in the CEs of A. subrufescens, L. edodes, and P. ostreatus: shikimic acid, trans-cinnamic acid, protocatechuic acid, 4-hydroxybenzoic acid, sinapic acid, 4-hydroxyphenylacetic acid, and the anthraquinone chrysophanol. According to Metabolomics Standards Initiative, these compounds were identified with a high-level confidence (level 1) based upon multiple dimensions of analysis [36]. 4-Hydroxybenzoic and protocatechuic acids have been previously reported in these three edible mushrooms [49-51] and were also identified in the 
current study. 4-Hydroxyphenylacetic acid were only identified in CEs from P. ostreatus, L. edodes stipe, and pileus. Koutrotsios et al. [52] also described that P. ostreatus contained 4-hydroxyphenylacetic acid; however, we report for the first time this compound in the extract of the L. edodes sporophore. Among the identified metabolites, chrysophanol was the most abundant phenolic compound contained in the three mushroom species. To date, this is the only report of this compound in the extracts of A. subrufescens, L. edodes, and P. ostreatus. Additionally, the presence of sinapic acid has not been reported before in CEs of L. edodes and A. subrufescens, but it has been previously described in extracts of P. ostreatus [53].

Other phenolic compounds present but not identified in the extracts might have contributed to their antimycotoxin activity. For instance, chlorophorin, iroko [28], vanillic acid [48], ferulic acid [54], chlorogenic, and caffeic acids [30] have been reported as FB1 inhibitors. As for the effects on mycotoxin production and mycelial growth, these effects were dose-dependent and perhaps, strain-dependent, in the present study. Ferrochio et al. [43] showed that ferulic acid activated the production of fumonisins at low concentrations ( 1 or $10 \mathrm{mM}$ ) while it inhibited them at higher levels (20-25 $\mathrm{mM})$. In addition, no effect of caffeic acid was observed [43], contrary to the results of Atanasova-Pénichon et al. [47]. In CEs, interactions between phenolic compounds and other components might complexify the response of the fungi when compared to pure compounds.

The differences between the extracts from stipe and pileus of L. edodes in their effects on mycotoxins are noteworthy, especially for the production of FB1, FB2, FB3, and the sum of these compounds, as well as for the production of FA, whereas no significant difference was observed between extracts from stipe and pileus of $A$. subrufescens. Differences in activity between extracts from stipes and pilei of a same species are probably due both to differences in composition and concentrations of phenolic compounds and to the antioxidant activity of these extracts. In a previous study where a white hybrid and two wild strains of Agaricus bisporus were cultivated simultaneously under the same conditions, the gills had more than three-fold higher phenolic content than the other parts of the fruiting body [55]. As discussed above, a same phenolic acid might activate the production of fumonisins at low concentrations and inhibit it at higher ones $[43,47]$. The main differences between stipe and pileus of L. edodes observed here were for higher concentrations in sinapic acid, 4-hydroxy-benzoic acid, and 4-hydroxy-phenylacetic acid in CEs from pileus. Zabka and Pavela [56] documented the antifungal activity of sinapic acid against $F$. verticillioides and other mycotoxigenic fungi but did not search for effects on mycotoxins. Also, hydroxy-benzoic and 4-hydroxy-phenylacetic acids inhibited the growth of F. oxysporum and Phytophthora capsici respectively, among other phytopathogenic fungi $[57,58]$. At the concentrations of the CEs used in our study, the presence of these phenolic acids had no limiting effect on the production of biomass by F. verticillioides that tends to be higher in presence of the CE from pileus, but they may be involved in decreasing fumonisins and FA production per unit of biomass.

Sinapic acid have been shown to affect the production of trichothecenes by F. culmorum and F. graminearum, which also respond by stimulation of ergosterol. This effect might be indirect since treatment with sinapic acid led to dramatic accumulation of its biosynthetic precursor ferulic acid, and chlorogenic acid biosynthesis [59]. Both compounds have caffeic acid as a common precursor, and an increased accumulation of caffeic acid may occur in the early incubation period of fungi in the presence of sinapic acid [59]. On the other hand, F. verticillioides was shown to be able to biotransform chlorogenic acid into caffeic acid that is very efficient in inhibiting fumonisins biosynthesis [30]. The observed difference in sinapic acid composition between extracts from stipe and pileus of L. edodes and its correlation with the production of fumonisins might be associated with a transitory accumulation of caffeic acid having an inhibiting effect. However, no sinapic acid was detected in extracts of As-P that inhibited the accumulation of fumonisins. So, other phenolic compounds may contribute to the inhibition of fumonisins biosynthesis.

The significant difference in inhibiting activity of extracts from stipe and pileus of L. edodes could be also associated with an overall difference in composition observed with the profiles of ions detected by liquid chromatography coupled to accurate mass spectrometry. None of the compounds tentatively 
identified resulted as specific of stipe or pileus and they have not been reported in the literature for their effect, neither on the production of fumonisins and FA by F. verticillioides nor on the production of other mycotoxins. However, it is noteworthy that phenylalanine identified in CEs of pileus of L. edodes at a significantly higher level than in stipes is also a precursor of the synthesis of caffeic acid, through the conversion into $t$-cinnamic and $p$-coumaric acids [59]. Moreover, farnesyl acetone was identified only in stipe extracts. This compound is a sesquiterpenoid commonly found in plant essential oils and plant extracts, having antimicrobial and antioxidant activities [60,61]. In animal cells, it has been shown to block DNA replication [62], but there is no published data on a putative effect on the production of fumonisins or fusaric acid by fungi. The remaining metabolomic profiles deserve to be more deeply exploited to identify specific molecules to each CE that could be candidates for explaining their differences as inhibitors of the production of fumonisins and fusaric acid by F. verticillioides, and, when available, their activity could be tested in concentration response analyses.

\section{Conclusions}

The present results support the hypothesis that cultivable edible mushrooms have a potential to be a source of natural products for inhibiting the production of fumonisins and FA by F. verticillioides. Using methanolic extracts of stipes and pilei from the same sporophores of L. edodes, few molecules have been pointed as candidates for explaining differences in activity between methanolic extracts. In coming works, the use of other extracts and a deeper exploitation of metabolic profiles will reinforce our ability to identify efficient combinations of molecules in the extracts responsible for the inhibition or the stimulation of production of both mycotoxins. In addition, bioassay-guided isolation of active compounds in fractions of the active CEs will be accomplished in order to contribute to the identification of novel antifungals and to be able to produce natural mushroom extracts with high anti-mycotoxin activities. As the biological origin of a compound or a more or less purified extract does not fully guarantee its safety, it will be necessary to evaluate their toxicity and thereby ensure the safety of such products before offering them for use in greenhouse or field conditions. A limit to the future development of such extracts as bio-control products could be the production cost and competition with food uses of mushrooms. However, because of their degrading capacities, it is possible to cultivate these mushrooms intended for the production of extracts on contaminated substrates and thus recycle them [35].

\section{Materials and Methods}

\subsection{Fungi}

Strains of Agaricus subrufescens (IE-832), Lentinula edodes (IE-40), and Pleurotus ostreatus (IE-38) were provided by the Unidad de Biotecnología de Hongos Comestibles y Medicinales of the Instituto de Ecología A.C. (UBHCM, INECOL), Veracruz, Mexico.

Two Fusarium verticillioides strains were used in the experiments. The strain of $F$. verticillioides Fv63 had been isolated from maize cultivated in France. It was provided by Research Unit Mycology and Food safety (MycSA), INRAE, France. A specimen is deposited at the International Centre for Microbial Resources-Filamentous Fungi (CIRM-CF) collection (Marseille, France), under the reference number BRFM 2251. The second strain of F. verticillioides (MY3) had been isolated from maize cultivated in Mexico. The strain of MY3 belongs to the fungal collection at Dr. Javier Plasencia's laboratory (Department of Biochemistry, Faculty of Chemistry, UNAM, Mexico City) and it was kindly provided by Dr. Diana Sánchez-Rangel (INECOL).

\subsection{Cultivation of Mushrooms}

The spawn for the three mushroom strains was prepared with sorghum grains and peat moss $2 \%$. Both components were soaked with tap water for $24 \mathrm{~h}$, and pre-cooked at $80^{\circ} \mathrm{C}$ for $15 \mathrm{~min}$. The peat moss and grains were drained for $1 \mathrm{~h}$, mixed in bags, and sterilized for $1.5 \mathrm{~h}$. Finally, the substrate was 
inoculated with plugs of mycelium from potato dextrose agar medium (PDA) and incubated at $25^{\circ} \mathrm{C}$ in darkness until the substrate was completely invaded.

The mushrooms were cultivated with different techniques at UBHCM. The cultivation of A. subrufescens was performed as in Martos and co-workers [63]. The substrate used was a commercial compost prepared for commercial production of the button mushroom A. bisporus, and delivered by Altex Rioxal, Veracruz, México. Wheat straw and poultry manure were the main ingredients for composting ( $55 \%$ and $27 \%$, respectively). Under aseptic conditions, $4 \mathrm{~kg}$ of compost were inoculated with $200 \mathrm{~g}$ of spawn and incubated at $25^{\circ} \mathrm{C}$ in darkness. When the mycelium invaded the substrate completely (46 days after inoculation), the compost was covered with $5 \mathrm{~cm}$ of a casing layer containing sand $30 \%$, peat moss $14 \%$, limestone $35 \%$, pulverized pumice $14 \%$, and water $7 \%$. After casing layer colonization, all crops were placed into a ventilated production room at $25^{\circ} \mathrm{C}$, and the relative humidity was always kept above $70 \%$.

To obtain the L. edodes' fruiting bodies, this fungus was cultivated following the technique recommended by Mata and Savoie [64]. Sixty grams of spawn were inoculated into $1.4 \mathrm{~kg}$ of barley straw added with $5 \%$ of oak sawdust and incubated at $25^{\circ} \mathrm{C}$ in darkness conditions for about 50 days. Then, the crops were placed into a production room at $18{ }^{\circ} \mathrm{C}, 75-85 \%$ relative humidity, and with controlled ventilation.

Finally, P. ostreatus was cultivated according to Guzmán et al. [65]. Two thousand grams of spawn were inoculated into $4 \mathrm{~kg}$ of barley straw and incubated at $25^{\circ} \mathrm{C}$ for 30 days. Subsequently, the crops were moved into the production room with the same conditions as for L. edodes cultivation.

Mushrooms were harvested at the commercial stage of development and immediately conditioned. Sporophores of A. subrufescens and L. edodes were separated by pileus and stipe, but not for P. ostreatus, due to the fact that both structures are not well differenced. They were frozen at $-80^{\circ} \mathrm{C}$ immediately after harvesting.

\subsection{Production of CEs from Sporophores}

Each part of the sporophore was freeze-dried (LABCONCO ${ }^{\circledR}$ FreeZone 2.5, Kansas City, MO, USA) for $48 \mathrm{~h}$ and later ground to a powder (Osterizer ${ }^{\circledR} 465-42$, Mexico city, Mexico). Dried and pulverized samples (44.0 and 73.9 $\mathrm{g}$ for As-P and As-S respectively, 137.0 and $59.9 \mathrm{~g}$ for Le-P and Le-S respectively, and $80.0 \mathrm{~g}$ for Po) were macerated using $\mathrm{MeOH}(1: 10 w / v)$ and shaking at $350 \mathrm{rpm}$ on a magnetic stirrer (StableTemp ${ }^{\mathrm{TM}}$, Lakeside, CA, USA). The extractions were set in darkness at $21^{\circ} \mathrm{C}$ and during $24 \mathrm{~h}$. Afterwards, the extraction liquors were recovered by filtration and the solvent was eliminated in a rotary evaporator under reduced pressure (BÜCHI Rotavapor RII) at $40^{\circ} \mathrm{C}$ to yield the corresponding CEs. The recovered mushroom materials were subjected to a second extraction procedure by using the same protocol and these CEs were combined with those obtained in the first extraction.

\subsection{Cultivation of F. verticillioides in Presence of Muschroom CEs}

Fusarium verticillioides Fv63 was cultivated on PDA in tubes and incubated at $25^{\circ} \mathrm{C}$ in darkness for 7 days. Thereafter, $6 \mathrm{~mL}$ of sterile distilled water was added to each culture, stirred, and diluted to obtain suspensions that contained $3.3 \times 10^{7}$ spores per $\mathrm{mL}$. The My 3 strain was incubated at $27^{\circ} \mathrm{C}$ for 7 days, and a suspension of $1 \times 10^{6}$ spores per $\mathrm{mL}$ was prepared.

A glucose, amylopectin, yeast extract, and peptone (GAYEP) medium was obtained by mixing $900 \mathrm{~mL}$ of a solution containing $40 \mathrm{~g} \mathrm{~L}^{-1}$ glucose and $10 \mathrm{~g} \mathrm{~L}^{-1}$ amylopectin from maize (autoclaved for $30 \mathrm{~min}$ at $105^{\circ} \mathrm{C}$ ) and $100 \mathrm{~mL}$ of a solution containing $1 \mathrm{~g} \mathrm{~L}^{-1}$ neopeptone and $1 \mathrm{~g} \mathrm{~L}^{-1}$ yeast extract, autoclaved for $20 \mathrm{~min}$ at $121{ }^{\circ} \mathrm{C}$ [54]. It was used for the mycotoxin production by the F. verticillioides strains.

For each strain, $100 \mu \mathrm{L}$ of spore suspensions were added in $25 \mathrm{~mL}$ flasks containing $10 \mathrm{~mL}$ of GAYEP medium [54]. The extracts (As-P, As-S, Le-P, Le-S, and Po) were dissolved in water, which was used as the vehicle, and independently added to the medium at a concentration of $2 \mathrm{mg} \mathrm{mL}^{-1}$. The spore suspension was inoculated into GAYEP with water as control. Fv63 was incubated with 
shaking ( $150 \mathrm{rpm}$ ) at $25^{\circ} \mathrm{C}$ for 14 days and My3 was incubated with $125 \mathrm{rpm}$ at $27^{\circ} \mathrm{C}$ for 14 days. For each experiment, cultures were made in triplicate.

\subsection{Mycelial Biomass Quantification}

For separating biomass, each culture was decanted into previously weighed $15 \mathrm{~mL}$ tubes. Then, they were centrifuged at $5000 \mathrm{rpm}$ and $4{ }^{\circ} \mathrm{C}$ for $10 \mathrm{~min}$. The fungal biomass was frozen at $-80^{\circ} \mathrm{C}$ and the supernatant was stored at $-20^{\circ} \mathrm{C}$ until mycotoxins were quantified. Fungal biomass was freeze-dried for $48 \mathrm{~h}$ and weighted.

\subsection{Analyses of Mycotoxins}

For the quantification of FB1, FB2, and FB3, fumonisins were extracted from culture media (supernatants) as described previously by Picot et al. [54]. Firstly, the $\mathrm{pH}$ of each sample was adjusted between 5.8 and 6.5 using sodium hydroxide (Sigma-Aldrich, Toluca, Mexico) (1 N) and hydrochloric acid (Sigma-Aldrich) (1 N) solutions. An ion exchange column (Blond Elut LRC-SAX $500 \mathrm{mg}$ Agilent technologies) was washed with $5 \mathrm{~mL}$ of $\mathrm{MeOH}$ high-performance liquid chromatography (HPLC)-grade (Interchim, Montluçon, France), and then $5 \mathrm{~mL} \mathrm{MeOH/Milli} \mathrm{Q}$ water (3:1, v:v). After column conditioning, $5 \mathrm{~mL}$ sample were added, and rinsed successively with $5 \mathrm{~mL} \mathrm{MeOH} / \mathrm{Milli} \mathrm{Q}$ water (3:1, v:v) and $3 \mathrm{~mL} \mathrm{MeOH}$. Finally, fumonisins were eluted with $10 \mathrm{~mL} \mathrm{MeOH} /$ acetic acid 1\%. The solvent evaporation was achieved in a heating system at $60{ }^{\circ} \mathrm{C}$ under nitrogen flow. Sample extracts were resuspended in $200 \mu \mathrm{L}$ of MeOH HPLC-grade, stirred for $30 \mathrm{~s}$, and filtered through a $0.2 \mu \mathrm{m}$ filter. Fumonisin concentrations were determined using a Shimadzu Prominence ultra-high-performance liquid chromatography system (UHPLC) chain composed of two LC-30AD pumps, and one autosampler (SIL-30AC) coupled to a fluorescence detector (RF-20A), where the derivatization with o-phthalaldehyde (OPA) and $\beta$-mercaptoethanol was performed automatically to make the fumonisins fluorescent. The mobile phase was $77 \%$ of $\mathrm{MeOH}$ in HPLC-grade with $23 \%$ of $\mathrm{NaH}_{2} \mathrm{PO}_{4} 2 \mathrm{H}_{2} \mathrm{O} 0.1 \mathrm{~mol} \mathrm{~L}^{-1}$. The flow was $1.2 \mathrm{~mL} \mathrm{~min}^{-1}$. The injection volume was $5 \mu \mathrm{L}$. The column was a Phenomenex, Kinetex C18, $150 \times 4.5 \mathrm{~mm}, 2.5 \mu \mathrm{m}$. Retention times of detected toxins were compared with commercial standards of FB1, FB2, and FB3 (Romer Labs, Austria). A calibration curve for each fumonisin was made in a concentration range of 1 to $50 \mathrm{ppm}\left(\mathrm{R}^{2}\right.$ values $\geq 0.97$ were considered for the linearity range). Data were expressed as $\mu \mathrm{g}$ of excreted fumonisin per $\mathrm{g}$ of dry biomass.

FA and FB1 were analyzed with a 1290 infinity Agilent UHPLC coupled to a 6460 Agilent triple quadrupole (QqQ) mass spectrometer (MS) with a dynamic multiple reaction monitoring (dMRM) method. The transition for FA and FB1 were $722.4>352.3$ and $180.1>134.1$ respectively, with collision energy of 20 and $40 \mathrm{~V}$, respectively. The polarity used for both compounds was positive and the ionization source was electrospray. Tubes containing $5 \mathrm{~mL}$ of culture medium (supernatant) were freeze-dried for $48 \mathrm{~h}$. Each obtained extract was dissolved in $1 \mathrm{~mL}$ of $\mathrm{MeOH} \geq 99.9 \%$ LC-MS ultra CHROMASOL ${ }^{\circledR}$ for UPLC (Sigma-Aldrich) with $0.1 \%$ of formic acid LC-MS grade (Sigma-Aldrich) by stirring for $5 \mathrm{~min}$, sonicated for $5 \mathrm{~min}$, and stirred for $30 \mathrm{~s}$ more. All samples were filtered through a $0.2 \mu \mathrm{m}$ filter. For UHPLC separation, the mobile phases were water with $0.1 \%$ of formic acid (A solution) (MS-grade, SIGMA-ALDRICH) and a solution of acetonitrile $90 \%$ with $0.1 \%$ of formic acid (MS-grade, SIGMA-ALDRICH) (B solution) (Table 3). The flow was $0.3 \mathrm{~mL} / \mathrm{min}$. The injection volume was $1 \mu \mathrm{L}$. The column was an Agilent, Zorbax SB-C18, $2.1 \times 50 \mathrm{~mm}, 1.8$ Microns. The column temperature was $40 \pm 0.8^{\circ} \mathrm{C}$.

The gradient elution was as follows: 1\% B for $3 \mathrm{~min}, 1 \%$ to $99 \%$ B for $9 \mathrm{~min}, 99 \%$ B for $2 \mathrm{~min}$, $1-99 \%$ B for $1 \mathrm{~min}$. Mass spectrometry conditions were set as follow: the gas temperature was $325^{\circ} \mathrm{C}$ and its flow rate was $6 \mathrm{~L} / \mathrm{min}$. Nebulizer was $45 \mathrm{psi} .350^{\circ} \mathrm{C}$ of sheath gas temperature and its flow rate was $11 \mathrm{~L} / \mathrm{min}$. 3500 of capillary voltage and 500 of nozzle voltage.

Retention times of detected toxins were compared with standards of FB1 and FA (Sigma-Aldrich ${ }^{\circledR}$ ). A calibration curve for each mycotoxin was made in a concentration range of 0.5 to $17 \mu \mathrm{M}$ $\left(R^{2}\right.$ values $\geq 0.97$ were considered for the linearity range). Data were expressed as $\mu \mathrm{g}$ of excreted 
FB1/FA per mg of dry biomass, and the percentage of inhibition of each treatment was calculated according to their respective negative control with the following equation:

$$
\% \text { inhibition }=100-\frac{(\mathrm{T} \times 100)}{\mathrm{C}}
$$

where: $\mathrm{T}=$ mycotoxin concentration in the treatment, and $\mathrm{C}=$ mycotoxin concentration in the control.

\subsection{Metabolomic Analysis and Chemical Profiling of the CEs}

Solutions of $20 \mathrm{mg} \mathrm{mL} \mathrm{mL}^{-1}$ of the six CEs were prepared in $\mathrm{MeOH} \geq 99.9 \%$ LC-MS ultra CHROMASOL $^{\circledR}$ for UHPLC-MS (Sigma-Aldrich) 0.1\% formic acid LC-MS-grade (Sigma-Aldrich). The samples were filtered with nylon membrane filters, with $0.2 \mu \mathrm{m}$ pore size (Acrodisc ${ }^{\circledR}$, Mexico City, Mexico). Finally, all samples were injected in a UHPLC (Acquity Class I, Waters ${ }^{\mathrm{TM}}$, Burnsville, MN, USA) coupled to a quadrupole time of flight (QTOF) high-resolution mass spectrometry analyzer (HRMS, Synapt G2-Si, Waters ${ }^{\mathrm{TM}}$ ).

The chromatography was performed on an Acquity BEH column $(1.7 \mu \mathrm{m}, 2.1 \times 50)$ with a column oven and sample temperatures of 40 and $15^{\circ} \mathrm{C}$, respectively. The mobile phase consisted of water and acetonitrile, both with $0.1 \%$ formic acid (Sigma). The gradient conditions of the mobile phases were $0-13 \mathrm{~min}$ liner gradient $1-80 \%$ of acetonitrile/0.1\% formic acid (total run time: $20 \mathrm{~min}$ ). The flow rate was $0.3 \mathrm{~mL} \mathrm{~min}^{-1}$ and $1 \mu \mathrm{L}$ of extract was injected. The mass spectrometric analysis was achieved with an electrospray ionization (ESI) source in positive mode with a capillary, sampling cone, and source offset voltages of 3000,40 , and $80 \mathrm{~V}$, respectively. The source temperature was $100{ }^{\circ} \mathrm{C}$ and the desolvation temperature was $20^{\circ} \mathrm{C}$. The desolvation gas flow was $600 \mathrm{~L} / \mathrm{h}$ and the nebulizer pressure was 6.5 Bar. The conditions used for MS analysis were mass range 50-1200 Da, function $1 \mathrm{CE}$, $6 \mathrm{~V}$, function 2 CER $10-30 \mathrm{~V}$, and scan time $0.5 \mathrm{~s}$.

For tentative identification of the metabolites from CEs with contrasted biological activity, a search of chemical compounds being present either in stipes or pilei of L. edodes, but not in both, was made using MassLynx software (Waters ${ }^{\circledR}$ ) by the comparison of the $\mathrm{m} / \mathrm{z}$ values of the precursor and products ions with those reported in the spectral databases, such as METLIN and FooDB (metlin.scripps.edu and foodb.ca, respectively). A mass accuracy error lower than 5 ppm was accepted.

\subsection{Analysis of Phenolic Compounds}

A total of 60 specific phenolic compounds were searched for identification and quantification in all CEs from sporophores by using the protocol reported by Juárez-Trujillo et al. [66]. All samples were analyzed by UHPLC-MS-QqQ with a dMRM as an acquisition method [66].

The chromatographic analysis was carried out on a ZORBAX SB-C18 column $(1.8 \mu \mathrm{m}, 2.1 \times 50 \mathrm{~mm}$; Agilent Technologies) with the column oven temperature at $40{ }^{\circ} \mathrm{C}$. The mobile phase consisted of $(\mathrm{A})$ water and (B) acetonitrile, both containing $0.1 \%$ formic acid. The gradient conditions of the mobile phase were: $0 \mathrm{~min}$ 1\% B, 0.1-40 min linear gradient 1-40\% B, 40.1-42 min linear gradient 40-90\% B, 42.1-44 min isocratic 90\% B, 44.1-46 min linear gradient 1-90\% B, 46.1-47 min 1\% B isocratic (total run time $47 \mathrm{~min}$ ). The flow rate was $0.1 \mathrm{~mL} / \mathrm{min}$, and $5 \mu \mathrm{L}$ was the sample injection volume. The ESI source was operated in positive and negative ionization modes. The desolvation temperature was $300{ }^{\circ} \mathrm{C}$, the cone gas (N2) flow was $5 \mathrm{~L} / \mathrm{min}$, the nebulizer pressure was $45 \mathrm{Psi}$, the sheath gas temperature was $250{ }^{\circ} \mathrm{C}$, the sheath gas flow was $11 \mathrm{~L} / \mathrm{min}$, the capillary voltage (positive and negative) was $3500 \mathrm{~V}$, and the nozzle voltage (positive and negative) was $500 \mathrm{~V}$. The fragmentor voltage was $100 \mathrm{~V}$ and the cell accelerator voltage was $7 \mathrm{~V}$ for all compounds. The identity was corroborated by co-elution with authentic standards under the same analytical conditions above described for each phenolic compound. A calibration curve in a concentration range of $0.5-17 \mu \mathrm{M}$ was prepared for quantitation of each compound ( $R^{2}$ values $\geq 0.97$ were considered for the linearity range). The dMRM transition for each compound was reported by Juárez-Trujillo et al. [62]. The data were processed using the 
MassHunter Workstation software, version B.06.00 (Agilent Technologies, Santa Clara, CA, USA), and the results were expressed as $\mu \mathrm{g} \mathrm{g}^{-1}$ of $\mathrm{CE}$.

\subsection{Data Analyses and Statisitics}

A factorial design housed in a completely randomized design were accomplished in the experimental stage. In order to determine some differences among CEs with respect to the control, the one-way analysis of variance (ANOVA) was used with R Studio ${ }^{\circledR}$ software (version 3.6.1, RStudio, Boston, MA, USA), at a level of significance set at 0.05 . Means for groups in homogeneous subsets were determined using the Tukey's multiple comparisons test (Tukey's post hoc test), at the 95\% confidence interval. Transformation data $(\log 10)$ was carried out when the results did not show normality (Shapiro-Wilk's test) or homoscedasticity (Bartlett's test) among treatments. All data were presented as mean values with their standard deviation indicated (mean $\pm \mathrm{SD}$ ).

In the untargeted metabolomics approach, differences between the metabolomes of the five CEs were visualized with a PCA using the retention times and the $m / z$ values obtained from the UHPLC-HRMS-QTOF analysis. After PCA, a volcano plot analysis was achieved to compare the datasets of the two CEs from L. edodes (stipe and pileus) and point out which metabolites were significantly different between the samples. The volcano plot also calculated fold change and $p$-values to allow a comparison of absolute value changes between the two group of means. The variable was reported as significant if the value was above a fold change of 2 , and the level of significance was set at 0.05 . Both analyses were carried out with four replicates. The PCA was accomplished with the MassLynx and MarkerLynx softwares (Waters ${ }^{\mathrm{TM}}$ ) and the volcano plot with the Metaboanalyst 4.0 software (metaboanalyst.ca, Montreal, Canada). All variables were Pareto-scaled prior to analyses.

Author Contributions: Conceptualization, J.-M.S., G.M., V.A., S.C., and J.A.G.-A.; Supervision J.-M.S., G.M., D.S., and J.A.G.-A., methodology, V.A., S.C., J.L.M.-V., and C.O.; investigation D.M., S.C., and J.L.M.-V.; writing-original draft preparation, D.M. and J.-M.S.; writing-review and editing, G.M., D.S., V.A., S.C., and J.A.G.-A. All authors have read and agreed to the published version of the manuscript.

Funding: This research was funded by CONACyT (No. 487726), FORDECyT (No. 273647 and 292399), and INECOL.

Acknowledgments: The authors would like to thank the technical staff of the Planta de Cultivo de Hongos Comestibles y Medicinales (Mycology Unit-INECOL, Red de Manejo Biotecnológico de Recursos, Xalapa, Mexico), Laboratorio de Química de Productos Naturales (BioMimic-INECOL, Red de Estudios Moleculares Avanzados, Xalapa, Mexico), and Mycologie et Sécurité des Aliments (MycSA-INRAE, Bordeaux, France) for their valuable assistance. The authors also thank Christopher Jeffrey (University of Nevada) for his assistance in the revision of this manuscript.

Conflicts of Interest: The authors declare no conflict of interest. The funders had no role in the design of the study; in the collection, analyses, or interpretation of data; in the writing of the manuscript, or in the decision to publish the results.

\section{References}

1. Stockmann-Juvala, H.; Savolainen, K. A review of the toxic effects and mechanisms of action of fumonisin B1. Hum. Exp. Toxicol. 2008, 27, 799-809. [CrossRef] [PubMed]

2. Smith, M.-C.; Madec, S.; Coton, E.; Hymery, N. Natural Co-Occurrence of Mycotoxins in Foods and Feeds and Their in vitro Combined Toxicological Effects. Toxins 2016, 8, 94. [CrossRef] [PubMed]

3. Oldenburg, E.; Höppner, F.; Ellner, F.; Weinert, J. Fusarium diseases of maize associated with mycotoxin contamination of agricultural products intended to be used for food and feed. Mycotoxin Res. 2017, 33, 167-182. [CrossRef] [PubMed]

4. Munkvold, G.P.; Arias, S.; Taschl, I.; Gruber-Dorninger, C. Mycotoxins in Corn: Occurrence, Impacts, and Management. In Corn; Elsevier BV: Amsterdam, The Netherlands, 2019; pp. 235-287.

5. Bartok, T.; Szécsi, Á.; Szekeres, A.; Ákos, M.; Bartók, M. Detection of new fumonisin mycotoxins and fumonisin-like compounds by reversed-phase high-performance liquid chromatography/electrospray ionization ion trap mass spectrometry. Rapid Commun. Mass Spectrom. 2006, 20, 2447-2462. [CrossRef] 
6. Munkvold, G.P. Fusarium Species and Their Associated Mycotoxins; Springer Science and Business Media LLC: Berlin/Heidelberg, Germany, 2016; pp. 51-106.

7. Marasas, W.F.O. Fumonisins: Their implications for human and animal health. Nat. Toxins 1995, 3, $193-198$. [CrossRef]

8. Alizadeh, A.M.; Roshandel, G.; Roudbarmohammadi, S.; Roudbary, M.; Sohanaki, H.; Ghiasian, S.A.; Taherkhani, A.; Semnani, S.; Aghasi, M. Fumonisin B1 Contamination of Cereals and Risk of Esophageal Cancer in a High Risk Area in Northeastern Iran. Asian Pac. J. Cancer Prev. 2012, 13, 2625-2628. [CrossRef]

9. IARC. Some traditional herbal medicines, some mycotoxins, naphthalene, and styrene. In International Agency for Research on Cancer Monographs on the Evaluation of Carcinogenic Risks to Humans; IARC Press: Lyon, France, 2002.

10. Missmer, S.A.; Suarez, L.; Felkner, M.; Wang, E.; Merrill, A.H.; Rothman, K.J.; Hendricks, K.A. Exposure to Fumonisins and the Occurrence of Neural Tube Defects along the Texas-Mexico Border. Environ. Health Perspect. 2006, 114, 237-241. [CrossRef]

11. Waes, J.G.-V.; Starr, L.; Maddox, J.; Aleman, F.; Voss, K.A.; Wilberding, J.; Riley, R.T. Maternal fumonisin exposure and risk for neural tube defects: Mechanisms in an in vivo mouse model. Birth Defects Res. Part A Clin. Mol. Teratol. 2005, 73, 487-497. [CrossRef]

12. Rafael, G.A.B.; Francisco, D.C.C.F.; Juliana, D.A.C.; Amilton, P.R.C.; Maria, M.G.P.N.; Maria, C.S.M. Fusarium spp. And fumonisin in feed for equine and its importance for occurrence of leukoencephalomalacia. Afr. J. Microbiol. Res. 2016, 10, 1248-1256. [CrossRef]

13. Reyes-Velázquez, W.P.; Anguiano-Sevilla, C.N.; Anguiano-Estrella, R.; Jiménez, L.A.; Torres-Morán, P.; Rojo, F. Niveles de fumonisinas en rastrojo de maíz para consumo equino en el estado de Jalisco. Rev. Mex. Cienc. Реси. 2018, 9, 846-854. [CrossRef]

14. Haschek, W.M.; Gumprecht, L.A.; Smith, G.; Tumbleson, M.E.; Constable, P.D. Fumonisin toxicosis in swine: An overview of porcine pulmonary edema and current perspectives. Environ. Health Perspect. 2001, 109, 251-257. [CrossRef]

15. Diniz, S.; Oliveira, R.C. Effects of fusaric acid on Zea mays L. seedlings. Phyton Int. J. Exp. Bot. 2009, 78, 155-160.

16. Stipanovic, R.D.; Puckhaber, L.; Liu, J.; Bell, A. Phytotoxicity of fusaric acid and analogs to cotton. Toxicon 2011, 57, 176-178. [CrossRef]

17. Dong, X.; Ling, N.; Wang, M.; Shen, Q.; Guo, S. Fusaric acid is a crucial factor in the disturbance of leaf water imbalance in Fusarium-infected banana plants. Plant Physiol. Biochem. 2012, 60, 171-179. [CrossRef]

18. Singh, V.K.; Singh, H.B.; Upadhyay, R.S. Role of fusaric acid in the development of 'Fusarium wilt' symptoms in tomato: Physiological, biochemical and proteomic perspectives. Plant Physiol. Biochem. 2017, 118, 320-332. [CrossRef]

19. Abdul, N.S.; Nagiah, S.; Chuturgoon, A.A. Fusaric acid induces mitochondrial stress in human hepatocellular carcinoma (HepG2) cells. Toxicon 2016, 119, 336-344. [CrossRef]

20. Ghazi, T.; Nagiah, S.; Tiloke, C.; Abdul, N.S.; Chuturgoon, A.A. Fusaric acid induces DNA damage and post-translational modifications of p53 in human hepatocellular carcinoma (HepG(2)) cells. J. Cell Biochem. 2017, 118, 3866-3874. [CrossRef]

21. Devnarain, N.; Tiloke, C.; Nagiah, S.; Chuturgoon, A.A. Fusaric acid induces oxidative stress and apoptosis in human cancerous oesophageal SNO cells. Toxicon 2017, 126, 4-11. [CrossRef]

22. Mamur, S.; Unal, F.; Yilmaz, S.; Erikel, E.; Yuzbasioglu, D. Evaluation of the cytotoxic and genotoxic effects of mycotoxin fusaric acid. Drug Chem. Toxicol. 2018, 43, 149-157. [CrossRef]

23. Porter, J.K.; Bacon, C.W.; Wray, E.M.; Hagler, W.M. Fusaric acid inFusarium moniliforme cultures, corn, and feeds toxic to livestock and the neurochemical effects in the brain and pineal gland of rats. Nat. Toxins 1995, 3, 91-100. [CrossRef]

24. Yin, E.S.; Rakhmankulova, M.; Kucera, K.; Filho, J.S.; Portero, C.E.; Narvaez-Trujillo, A.; Holley, S.A.; Strobel, S.A. Fusaric acid induces a notochord malformation in zebrafish via copper chelation. BioMetals 2015, 28, 783-789. [CrossRef]

25. Bacon, C.W.; Porter, J.K.; Norred, W.P. Toxix interaction of fumonisin B1 and fusaric acid measured by injection into fertile chiclen eggs. Mycopathologia 1995, 129, 29-35. [CrossRef]

26. Magan, N.; Aldred, D. Post-harvest control strategies: Minimizing mycotoxins in the food chain. Int. J. Food Microbiol. 2007, 119, 131-139. [CrossRef] 
27. Nava-Pérez, E.; García-Gutiérrez, C.; Camacho-Báez, J.R.; Vázquez-Montoya, E.L. Bioplaguicidas: Una opción para el control biológico de plagas. Ra Ximhai 2012, 8, 17-30. [CrossRef]

28. Beekrum, S.; Govinden, R.; Padayachee, T.; Odhav, B. Naturally occurring phenols: A detoxification strategy for fumonisin B1. Food Addit. Contam. 2003, 20, 490-493. [CrossRef]

29. Telles, A.C.; Kupski, L.; Furlong, E.B. Phenolic compound in beans as protection against mycotoxins. Food Chem. 2017, 214, 293-299. [CrossRef]

30. Atanasova-Penichon, V.; Bernillon, S.; Marchegay, G.; Lornac, A.; Pinson-Gadais, L.; Ponts, N.; Zehraoui, E.; Barreau, C.; Richard-Forget, F. Bioguided Isolation, Characterization, and Biotransformation by Fusarium verticillioides of Maize Kernel Compounds That Inhibit Fumonisin Production. Mol. Plant-Microbe Interact. 2014, 27, 1148-1158. [CrossRef]

31. Ferruz, E.; Loran, S.; Herrera, M.; Gimenez, I.; Bervis, N.; Barcena, C.; Carramiñana, J.J.; Juan, T.; Herrera, A.; Ariño, A. Inhibition of Fusarium Growth and Mycotoxin Production in Culture Medium and in Maize Kernels by Natural Phenolic Acids. J. Food Prot. 2016, 79, 1753-1758. [CrossRef]

32. Pilu, R.; Cassani, E.; Sirizzotti, A.; Petroni, K.; Tonelli, C.; Pilu, R. Effect of flavonoid pigments on the accumulation of fumonisin B1 in the maize kernel. J. Appl. Genet. 2010, 52, 145-152. [CrossRef]

33. Robles-Hernández, L.; Cecilia-González- Franco, A.; Soto-Parra, J.M.; Montes-Domínguez, F. Review of agricultural and medicinal applications of basidiomycete mushrooms. Tecnociencia Chihuahua 2002, 2, 95-107.

34. Alves, M.; Ferreira, I.C.; Dias, J.; Teixeira, V.; Martins, A.; Pintado, M.M. A Review on Antifungal Activity of Mushroom (Basidiomycetes) Extracts and Isolated Compounds. Curr. Top. Med. Chem. 2013, 13, 2648-2659. [CrossRef]

35. Savoie, J.-M.; Mata, G.; Penichon, V.A.; Foulonge-Oriol, M. Using mushroom-forming fungi in preventing and reducing mycotoxins in cereal products. Sci. Fungorum 2019, 49, e1256. [CrossRef]

36. Sumner, L.W.; Amberg, A.; Barrett, D.A.; Beale, M.H.; Beger, R.; Daykin, C.A.; Fan, T.W.-M.; Fiehn, O.; Goodacre, R.; Griffin, J.; et al. Proposed minimum reporting standards for chemical analysis Chemical Analysis Working Group (CAWG) Metabolomics Standards Initiative (MSI). Metabolomics 2007, 3, $211-221$. [CrossRef]

37. Sasaki, S.H.; Linhares, R.E.; Nozawa, C.M.; Montalván, R.; Paccola-Meirelles, L.D. Strains of Lentinula edodes suppress growth of phytopathogenic fungi and inhibit Alagoas serotype of vesicular stomatitis virus. Braz. J. Microbiol. 2001, 32, 52-55. [CrossRef]

38. Chen, J.T.; Huang, J.W. Antimicrobial activity of edible mushroom culture filtrates on plant pathogens. Plant Pathol. Bull. 2010, 4, 261-270.

39. Stojković, D.; Reis, F.S.; Glamočlija, J.; Ćirić, A.; Barros, L.; Van Griensven, L.J.L.D.; Ferreira, I.C.; Sokovic, M. Cultivated strains of Agaricus bisporus and A. brasiliensis: Chemical characterization and evaluation of antioxidant and antimicrobial properties for the final healthy product natural preservatives in yoghurt. Food Funct. 2014, 5, 1602. [CrossRef]

40. Ishihara, A.; Goto, N.; Kikkawa, M.; Ube, N.; Ushijima, S.; Ueno, M.; Ueno, K.; Osaki-Oka, K. Identification of antifungal compounds in the spent mushroom substrate of Lentinula edodes. J. Pestic. Sci. 2018, 43, 108-113. [CrossRef]

41. Spremo, N.; Atlagic, K.; Rakić, M.; Janjušević, L.; Ignjatov, M.; Bjelić, D.; Karaman, M. Antifungal activity of macrofungi extracts on phytopathogenic fungal strains of genera Fusarium sp. and Alternaria sp. Zb. Matic Srp. Prir. Nauk. 2017, 133, 231-240. [CrossRef]

42. Nowacka-Jechalke, N.; Nowak, R.; Drozd, M.; Olech, M.; Los, R.; Malm, A. Analysis of phenolic constituents, antiradical and antimicrobial activity of edible mushrooms growing wild in Poland. LWT 2014, 59, 689-694. [CrossRef]

43. Ferrochio, L.; Cendoya, E.; Farnochi, M.C.; Massad, W.; Ramirez, M.L. Evaluation of ability of ferulic acid to control growth and fumonisin production of Fusarium verticillioides and Fusarium proliferatum on maize based media. Int. J. Food Microbiol. 2013, 167, 215-220. [CrossRef]

44. Dambolena, J.S.; Lopez, A.; Canepa, M.; Theumer, M.; Zygadlo, J.; Rubinstein, H. Inhibitory effect of cyclic terpenes (limonene, menthol, menthone and thymol) on Fusarium verticillioides MRC 826 growth and fumonisin B1 biosynthesis. Toxicon 2008, 51, 37-44. [CrossRef]

45. Ansari, M.A.; Anurag, A.; Fatima, Z.; Hameed, S. Natural phenolic compounds: A potential antifungal agent. In Microbial Pathogens and Strategies for Combating Them: Science, Technology and Education; Méndez-Vilas, A., Ed.; Formatex Research Center: Badajoz, Spain, 2013; pp. 189-195. 
46. Ponts, N. Mycotoxins are a component of Fusarium graminearum stress-response system. Front. Microbiol. 2015, 6, 1800. [CrossRef]

47. Atanasova-Penichon, V.; Barreau, C.; Richard-Forget, F. Antioxidant Secondary Metabolites in Cereals: Potential Involvement in Resistance to Fusarium and Mycotoxin Accumulation. Front. Microbiol. 2016, 7, 6182. [CrossRef]

48. Samapundo, S.; Devlieghere, F.; de Meulenaer, B.; Geeraerd, A.; van Impe, J.; Debevere, J. Predictive modelling of the individual and combined effect of water activity and temperature on the radial growth of Fusarium verticilliodes and F. proliferatum on corn. Int. J. Food Microbiol. 2005, 105, 35-52. [CrossRef]

49. Kim, M.-Y.; Seguin, P.; Ahn, J.-K.; Kim, J.-J.; Chun, S.-C.; Kim, E.-H.; Seo, S.-H.; Kang, E.-Y.; Kim, S.-L.; Park, Y.-J.; et al. Phenolic Compound Concentration and Antioxidant Activities of Edible and Medicinal Mushrooms from Korea. J. Agric. Food Chem. 2008, 56, 7265-7270. [CrossRef]

50. Reis, F.S.; Martins, A.; Barros, L.; Ferreira, I.C. Antioxidant properties and phenolic profile of the most widely appreciated cultivated mushrooms: A comparative study between in vivo and in vitro samples. Food Chem. Toxicol. 2012, 50, 1201-1207. [CrossRef]

51. Carneiro, A.A.; Ferreira, I.C.; Dueñas, M.; Barros, L.; da Silva, R.; Gomes, E.; Santos-Buelga, C.; Dueñas, M. Chemical composition and antioxidant activity of dried powder formulations of Agaricus blazei and Lentinus edodes. Food Chem. 2013, 138, 2168-2173. [CrossRef]

52. Koutrotsios, G.; Kalogeropoulos, N.; Stathopoulos, P.; Kaliora, A.C.; Zervakis, G.I. Bioactive compounds and antioxidant activity exhibit high intraspecific variability in Pleurotus ostreatus mushrooms and correlate well with cultivation performance parameters. World J. Microbiol. Biotechnol. 2017, 33, 655. [CrossRef]

53. Koutrotsios, G.; Kalogeropoulos, N.; Kaliora, A.C.; Zervakis, G.I. Toward an Increased Functionality in Oyster (Pleurotus) Mushrooms Produced on Grape Marc or Olive Mill Wastes Serving as Sources of Bioactive Compounds. J. Agric. Food Chem. 2018, 66, 5971-5983. [CrossRef]

54. Picot, A.; Atanasova-Penichon, V.; Pons, S.; Marchegay, G.; Barreau, C.; Pinson-Gadais, L.; Roucolle, J.; Daveau, F.; Caron, D.; Richard-Forget, F. Maize Kernel Antioxidants and Their Potential Involvement in Fusarium Ear Rot Resistance. J. Agric. Food Chem. 2013, 61, 3389-3395. [CrossRef]

55. Savoie, J.-M.; Minvielle, N.; Largeteau, M.L. Radical-scavenging properties of extracts from the white button mushroom, Agaricus bisporus. J. Sci. Food Agric. 2008, 88, 970-975. [CrossRef]

56. Žabka, M.; Pavela, R. Antifungal efficacy of some natural phenolic compounds against significant pathogenic and toxinogenic filamentous fungi. Chemosphere 2013, 93, 1051-1056. [CrossRef]

57. Lattanzio, V.; de Cicco, V.; di Venere, D.; Lima, M.; Salerno, M. Antifungal activity of phenolics against different storage fungi. Ital. J. Food Sci. 1994, 6, 23-30.

58. Ko, H.-S.; Jin, R.-D.; Krishnan, H.B.; Lee, S.-B.; Kim, K.-Y. Biocontrol Ability of Lysobacter antibioticus HS124 Against Phytophthora Blight Is Mediated by the Production of 4-Hydroxyphenylacetic Acid and Several Lytic Enzymes. Curr. Microbiol. 2009, 59, 608-615. [CrossRef]

59. Kulik, T.; Stuper-Szablewska, K.; Bilska, K.; Buśko, M.; Ostrowska-Kołodziejczak, A.; Załuski, D.; Perkowski, J. Sinapic Acid Affects Phenolic and Trichothecene Profiles of F. culmorum and F. graminearum Sensu Stricto. Toxins 2017, 9, 264. [CrossRef]

60. Abd-Elgawad, A.; ElShamy, A.I.; Al-Rowaily, S.; El-Amier, Y.A. Habitat Affects the Chemical Profile, Allelopathy, and Antioxidant Properties of Essential Oils and Phenolic Enriched Extracts of the Invasive Plant Heliotropium Curassavicum. Plants 2019, 8, 482. [CrossRef]

61. Nathan, V.K.; Rani, M.E.; Rathinasamy, G.; Dhiraviam, K.N. Antioxidant and Antimicrobial Potential of Natural Colouring Pigment Derived from Bixa orellana L. Seed Aril. Proc. Natl. Acad. Sci. USA 2017, 89, 137-143. [CrossRef]

62. Meigs, T.E.; Sherwood, S.W.; Simoni, R.D. Farnesyl Acetate, a Derivative of an Isoprenoid of the Mevalonate Pathway, Inhibits DNA Replication in Hamster and Human Cells. Exp. Cell Res. 1995, 219, 461-470. [CrossRef]

63. Martos, E.T.; Zied, D.C.; Junqueira, P.P.G.; Rinker, D.L.; da Silva, R.; Toledo, R.C.C.; Dias, E.S. Casing layer and effect of primordia induction in the production of Agaricus subrufescens mushroom. Agric. Nat. Resour. 2017, 51, 231-234. [CrossRef]

64. Mata, G.; Savoie, J.-M. Shiitake cultivation on straw: An alternative for subtropical regions. In Updates on Tropical Mushrooms. Basic and Applied Research, 1st ed.; Sánchez, J.E., Mata, G., Royse, D.J., Eds.; El Colegio de la Frontera Sur: San Cristóbal de Las Casas, Mexico, 2018; pp. 115-134. ISBN 978-607-8429-60-8. 
65. Guzmán, G.; Mata, G.; Salmones, D.; Soto-Velazco, C.; Guzmán-Dávalos, L. El Cultivo de Hongos Comestibles con Especial Atención a Especies Tropicales y Subtropicales en Esquilmos y Residuos Agroindustriales, 3rd ed.; Instituto Politécnico Nacional: Ciudad de Mexico, Mexico, 2013.

66. Juárez-Trujillo, N.; Monribot-Villanueva, J.L.; Alvarado-Olivarez, M.; Solano, G.L.; Guerrero-Analco, J.A.; Jiménez-Fernández, M. Phenolic profile and antioxidative properties of pulp and seeds of Randia monantha Benth. Ind. Crop. Prod. 2018, 124, 53-58. [CrossRef]

(C) 2020 by the authors. Licensee MDPI, Basel, Switzerland. This article is an open access article distributed under the terms and conditions of the Creative Commons Attribution (CC BY) license (http://creativecommons.org/licenses/by/4.0/). 